A

Differentially Methylated Loci per Gene Location

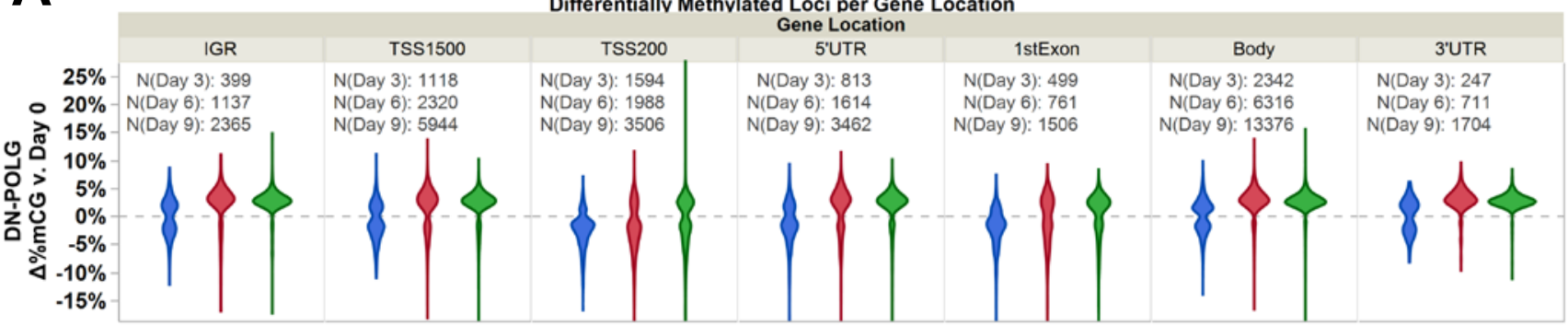

\title{
B
}

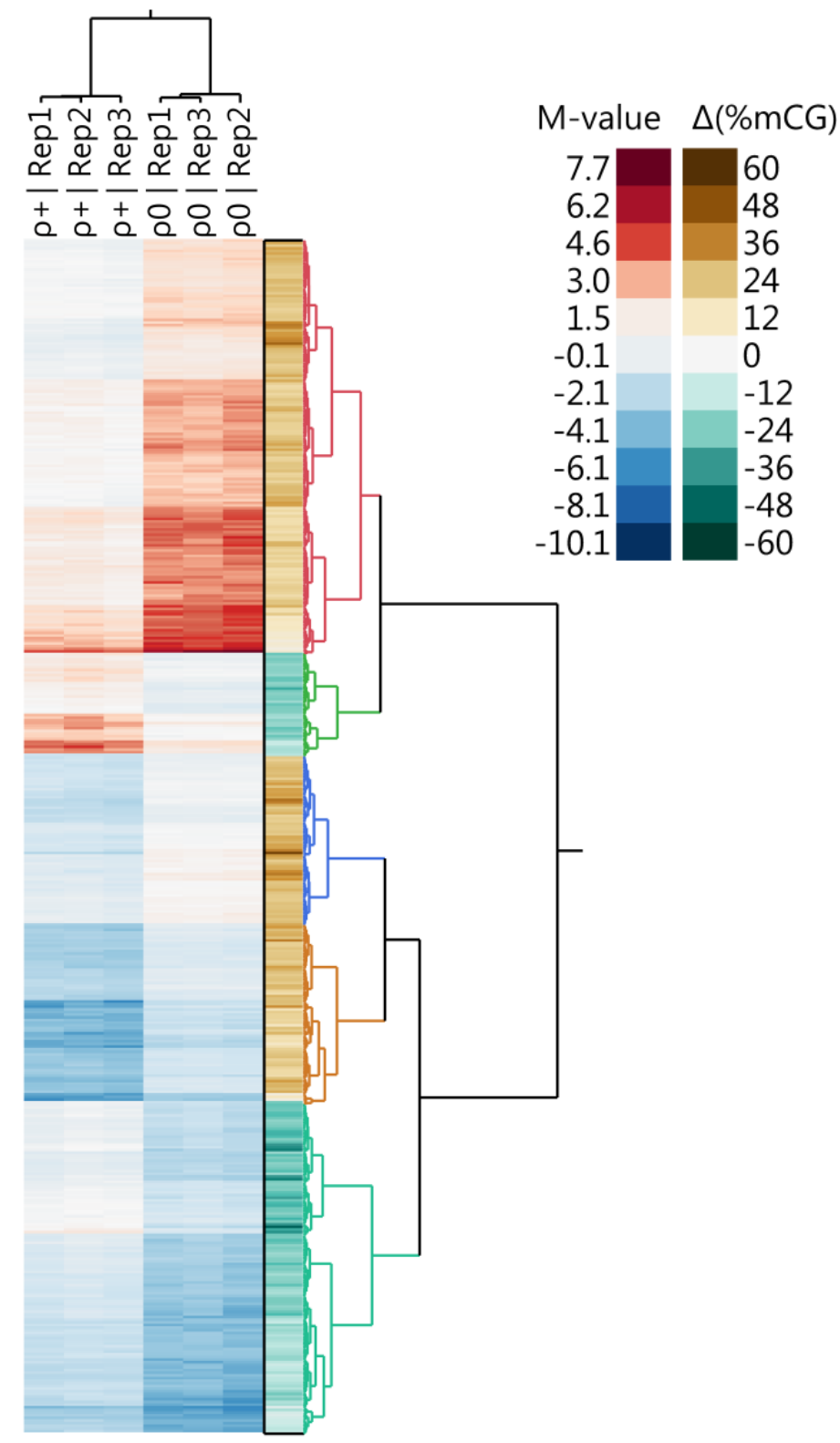


C
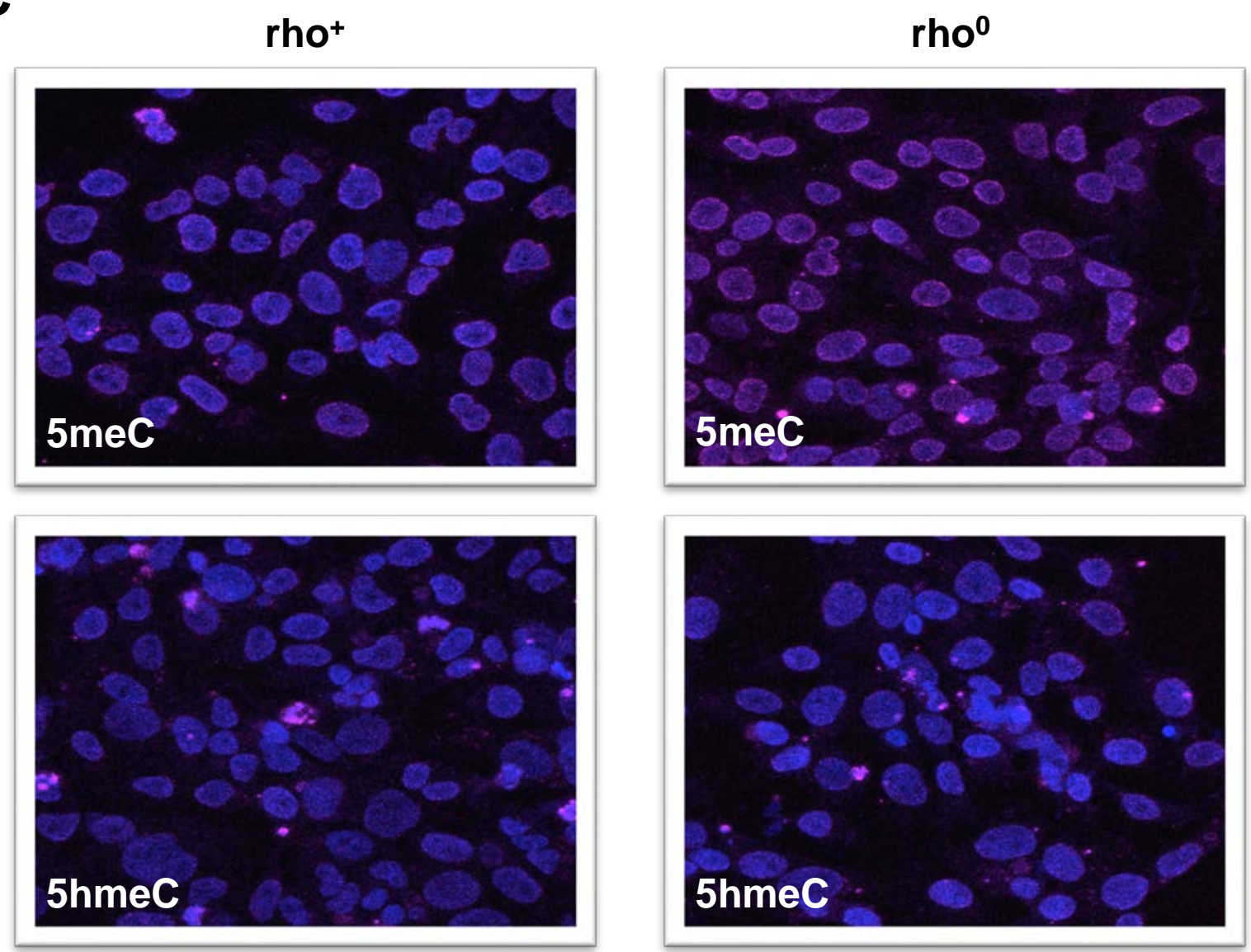

D

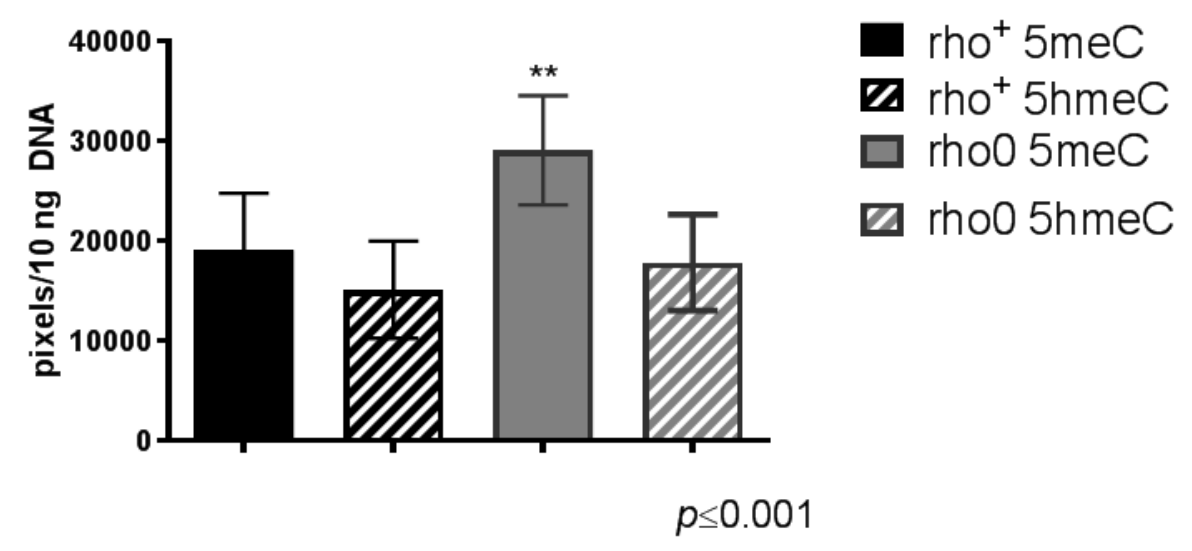


E

d3/d0: 63 DMEGs

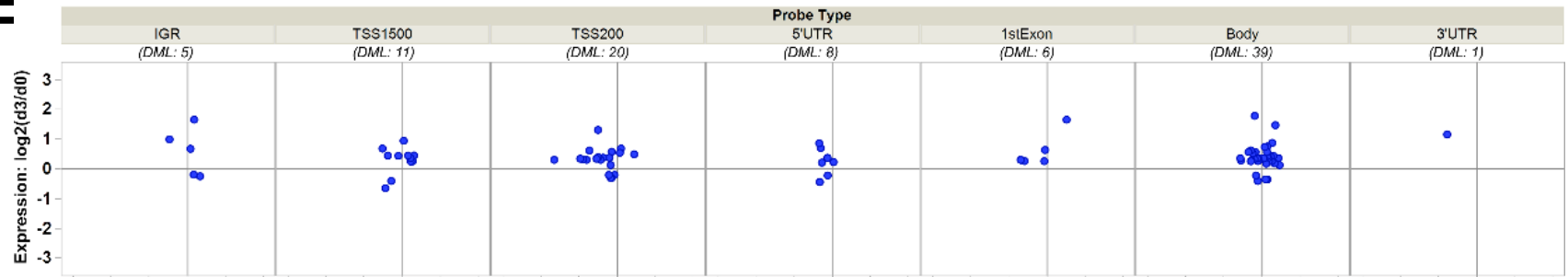

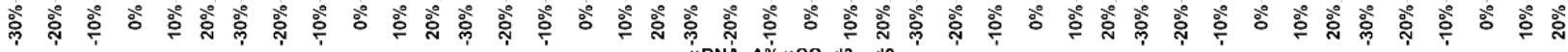

d6/d0: 978 DMEGs

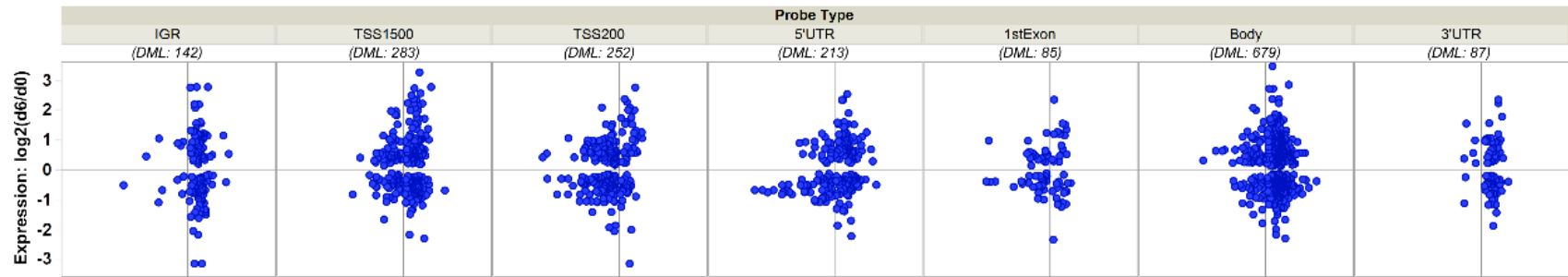

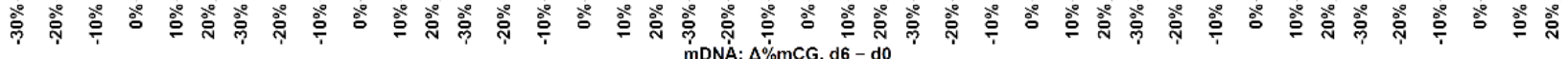

d9/d0: 879 DMEGs

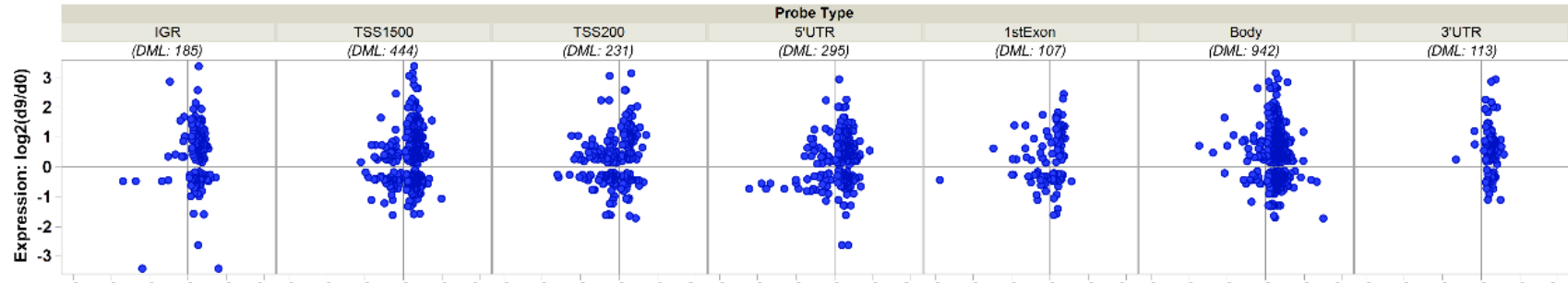

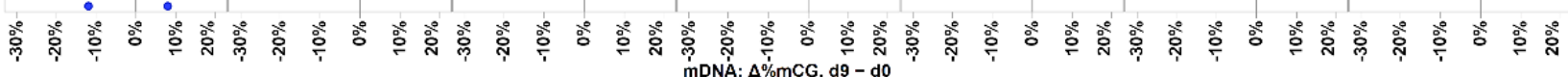

$\mathbf{F}$

DN-POLG: Total DEGs

DN-POLG: Total DMGs

P-value (Chi-sq)

Odds Ratio (O/E)
2,850

12,461

4.0E-07

0.81

\begin{tabular}{|l|c|c|c|c|c|}
\cline { 2 - 6 } \multicolumn{1}{c|}{} & \multicolumn{2}{c|}{ Observed } & \multicolumn{2}{c|}{ Expected } & \multicolumn{1}{c|}{} \\
\cline { 2 - 6 } \multicolumn{1}{c|}{} & DMG & Not DMG & DMG & Not DMG & Rate \\
\hline DEG & 1,627 & 1,223 & $1,749.1$ & $1,100.9$ & $57.09 \%$ \\
\hline Not DEG & 10,834 & 6,620 & $10,711.9$ & $6,742.1$ & $62.07 \%$ \\
\hline
\end{tabular}

$G$

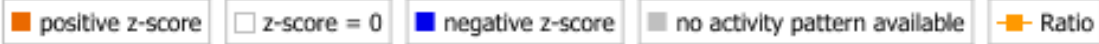

$\begin{array}{lllllllllllllllll}0.0 & 0.1 & 0.2 & 0.3 & 0.4 & 0.5 & 0.6 & 0.7 & 0.8 & 0.9 & 1.0 & 1.1 & 1.2 & 1.3 & 1.4 & 1.5 & 1.6\end{array}$

Folate Transformations I

Pyridoxal 5'-phosphate Salvage Pathway

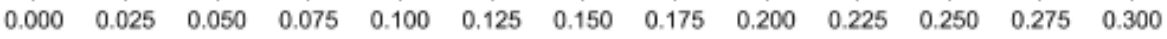




\section{Gene Overall}

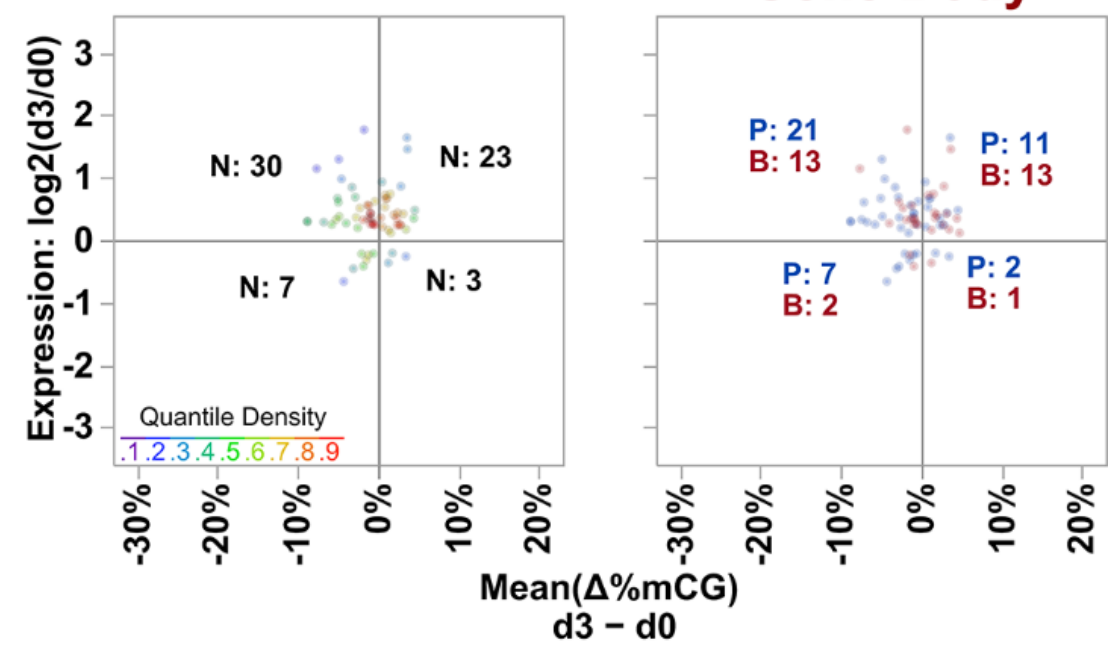

Gene Promoter Gene Body
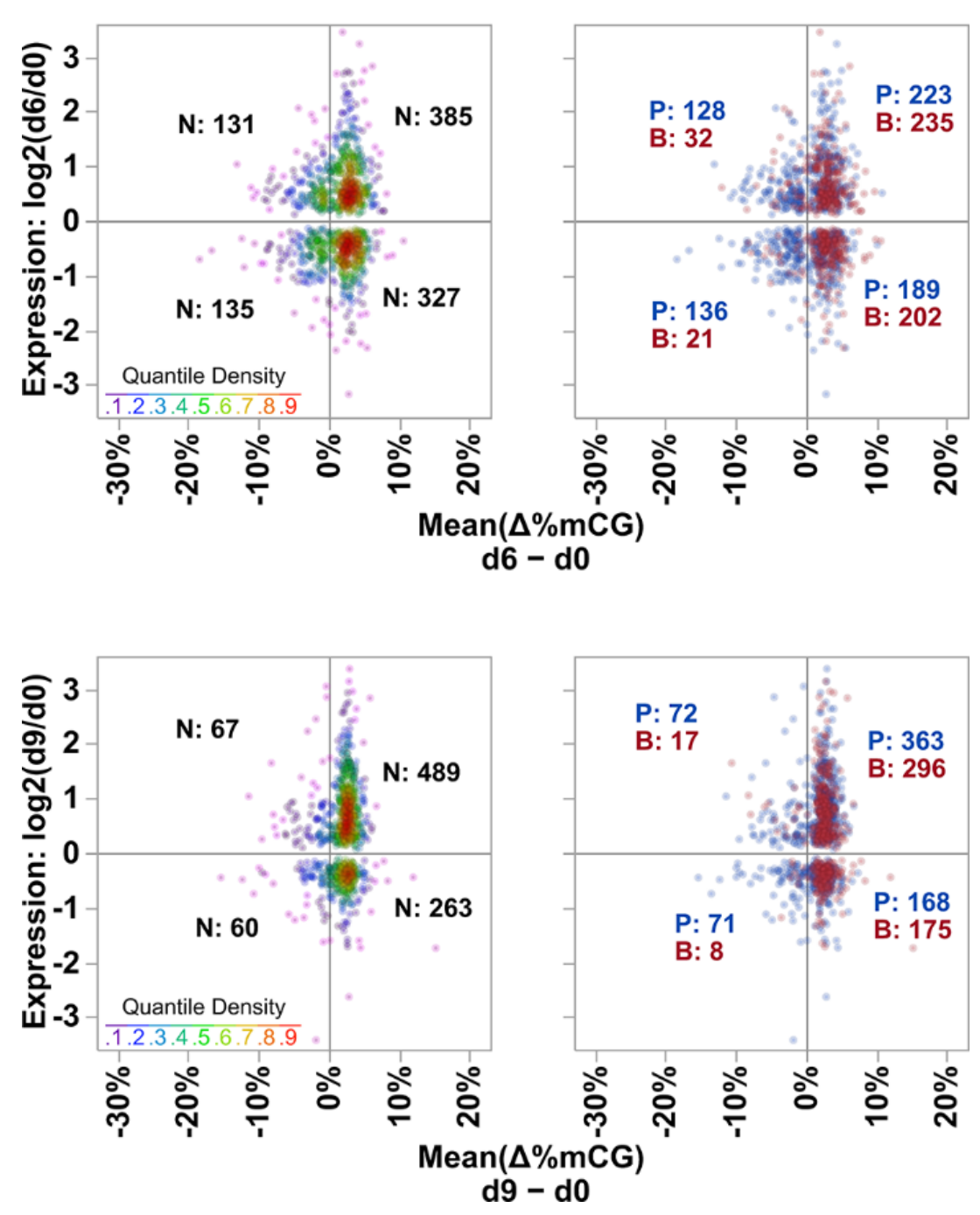